\title{
Prevalence of Self-Reported Work-related Musculoskeletal Symptoms among Software Employees in Hyderabad, India
}

\author{
Madhubabu Kothapalli ${ }^{1}$ \\ ${ }^{1}$ PREVENTA CURO, Centre for Workplace Healthcare \& Research, Q city, Gachibowli, Hyderabad -500032, \\ India.
}

DOI: https://doi.org/10.52403/ijrr.20220111

\begin{abstract}
Background: This study has been carried out to analyze the prevalence of self-reported workrelated musculoskeletal symptoms among software professionals and to utilize the findings to design an effective preventive interventional program for WRMSDs.
\end{abstract}

Subjects \& Methods: This cross-sectional descriptive data analysis was done among 665 software employees both male and female from various companies in Q city Tech Park, Hyderabad. Data collected with "Cornell Musculoskeletal Discomfort Questionnaire” (CMDQ).

Results: A total of 640 subjects were eligible for this study. Prevalence of WRMSDs to be $67 \%$. The most common sites of reported symptoms are neck (65.0\%), upper back (56.4\%), lower back (62.6\%), right shoulder (41.4\%), left shoulder (35.4\%) and right thigh $(41.4 \%)$. Women were more likely to report symptoms in neck, lower back and both shoulder region than men $(\mathrm{p}<0.05)$. Discomforts in neck, lower back and right shoulder are greatly shown impact on work performance.

Conclusion: WRMSDs are highly prevalent is software professionals and women at more risk than men. These findings indicate the need for more attention to WRMSDs and design of effective preventive strategies.

Key Words: musculoskeletal pain, Prevalence, software professionals, work related musculoskeletal disorders

\section{INTRODUCTION}

Work related musculoskeletal disorders (WRMSDs) in computer users has become major concern in recent years (1). Long term use of computer and sitting at desk for long time are main risk factors in WRMSDs (2). These WRMSDs describe a wide range of degenerative and inflammatory changes that cause pain and functional impairment and muscular pain is a usual outcome (3).

Subjective assessment of symptoms is mostly helpful to study the association between musculoskeletal disorders and computer work. This will give a better understanding of WMSDs as well as good rationale for the design of preventive interventional programs (4). The aim of the study was to analyze the frequency of selfreporting musculoskeletal symptoms and their impact on work performance in computer users. The findings of the study can be utilized in the design of preventive interventions for WRMSDs.

\section{MATERIALS \& METHODS Subjects}

The study was done with convenient sampling method, included 665 software employees both male and female from various companies in $\mathrm{Q}$ city tech park, Hyderabad. The study subjects age ranging from 21-43 years old. No objection consent was obtained from all the study participants. 


\section{Inclusion and exclusion criteria}

Inclusion criteria is the subjects with full time software employment for more than 1 year, both genders age ranging from $21-50$ years old and work time at office is more than 7 hours per day.

Exclusion criteria comprised of participants with old injuries or trauma, Road traffic accidents, recent surgeries or medical treatment and any history of psychological problems and their treatments.

\section{Study Design}

This is a cross-sectional descriptive study to investigate prevalence incident rate. All the study subjects were given a questionnaire with two parts. One with demographic data questionnaire and the other one is "Cornell Musculoskeletal Discomfort Questionnaire (CMDQ)". The CMDQ is a 54-item questionnaire which contains a body chart and questions about musculoskeletal pain and discomfort incidence in 20 parts of the body over the past week. The questionnaire has different versions for men and women. All the study participants were clearly explained about CMDQ independently and requested to complete questionnaire. The demographic data collected with separate questionnaire, consists of details like age, gender, height, weight, marital status, years of experience, number of working hours per day.

Statistical analysis estimates musculoskeletal discomforts in study subjects. It assesses frequency and impact on work performance for last 7 days from 11 various risk prone body parts like neck, shoulders, back, upper arms, forearms, wrists, waist, hips, upper legs, knees and lower legs.

\section{Statistical Analysis}

Descriptive statistics was used to analyze the data collected from all the study participants. SPSS version 23 software used to perform all the statistical analysis. The Chi - Square test analysis used to validate statistical significance between the musculoskeletal discomfort symptom and possible risk factors in study participants. Study results were evaluated at 95\% CI level and p less than 0.05 was evaluated as statistical significance.

\section{Ethics statement}

The study was an analysis of dataset so ethics committee approval not required. Informed consent was obtained from subjects at the time of original data collection.

\section{RESULT}

Table: 1 - Demographic data
\begin{tabular}{|l|l|l|}
\hline Characteristics & Frequency & Percentage (\%) \\
\hline Gender & 390 & $61 \%$ \\
\hline Men & 250 & $39 \%$ \\
\hline Women & 434 & $67.8 \%$ \\
\hline Age (years) & 168 & $26.2 \%$ \\
\hline $21-30$ & 38 & $5.9 \%$ \\
\hline $31-40$ & 195 & $30.4 \%$ \\
\hline $41-50$ & 445 & $69.6 \%$ \\
\hline Computer use time (hours/day) \\
\hline Less than 7 hours & \multicolumn{2}{|l|}{} \\
\hline More than 7 hours &
\end{tabular}

Table-2: Prevalence of self-reported symptoms in last 7 days according to body region.

Body location $\quad$ Symptoms during last work week $(n=640)$

\begin{tabular}{|c|c|c|}
\hline & Number & $\%$ \\
\hline Neck & 435 & $65.0 \%$ \\
\hline \multicolumn{3}{|l|}{ Back } \\
\hline Upper back & 361 & $56.4 \%$ \\
\hline Lower back & 432 & $62.6 \%$ \\
\hline \multicolumn{3}{|l|}{ Shoulder } \\
\hline Right & 265 & $41.4 \%$ \\
\hline Left & 227 & $35.4 \%$ \\
\hline \multicolumn{3}{|l|}{ Upper arm } \\
\hline Right & 209 & $32.6 \%$ \\
\hline Left & 170 & $26.5 \%$ \\
\hline \multicolumn{3}{|l|}{ Forearm } \\
\hline Right & 212 & $33.1 \%$ \\
\hline Left & 170 & $26.5 \%$ \\
\hline \multicolumn{3}{|l|}{ Wrist } \\
\hline Right & 230 & $35.9 \%$ \\
\hline Left & 134 & $20.9 \%$ \\
\hline \multicolumn{3}{|l|}{ Hip/buttocks } \\
\hline Right & 94 & $14.6 \%$ \\
\hline Left & 80 & $12.5 \%$ \\
\hline \multicolumn{3}{|l|}{ Thigh } \\
\hline Right & 79 & $41.4 \%$ \\
\hline Left & 64 & $10.0 \%$ \\
\hline \multicolumn{3}{|l|}{ Knee } \\
\hline Right & 99 & $15.4 \%$ \\
\hline Left & 51 & $7.9 \%$ \\
\hline \multicolumn{3}{|l|}{ Lower leg } \\
\hline Right & 84 & $13.1 \%$ \\
\hline Left & 56 & $8.7 \%$ \\
\hline
\end{tabular}

A total of 640 study subjects included in this study $(\mathrm{n}=640)$. The other 25 participants excluded due to history of 
injuries and underwent pain treatments recently. Demographic data presented in table. 1 shows that of all study subjects, 390 (61\%) male and 250 (39\%) was female. Majority of the participants aged between 21 - 40 years old. Least number was presented between 41 - 50 years age group. Regarding computer usage time, 195 (30.4\%) was reported less than 7 hours in a day and 445 (69.6\%) were working more than 7 hours in a day.

In all, 429 (67\%) subjects reported symptoms in last 7 days. Most common musculoskeletal strain region reported by participants are neck (65.0\%), upper back (56.4\%), lower back (62.6\%), right shoulder (41.4\%), left shoulder (35.4\%) and right thigh (41.4\%). Participants less commonly reported symptoms in body regions like knees (23.4\%) and lower leg (21.8\%).

Compare to men, women have the higher prevalence rate of WMSDs across various body regions over the past 7 days. However, the difference is statistically significant for neck, lower back and both shoulders. (Chi-square analysis, $\mathrm{p}<0.05$ ) (Table -3)

Table - 3: Prevalence of Work-related musculoskeletal symptoms during previous 7 working days, according to gender.

\begin{tabular}{|c|c|c|c|c|c|}
\hline \multirow[t]{3}{*}{ Body region } & \multicolumn{4}{|c|}{ Gender } & \multirow[t]{3}{*}{$\mathbf{P}$} \\
\hline & \multicolumn{2}{|c|}{$\begin{array}{r}\text { Male } \\
\end{array}$} & \multicolumn{2}{|c|}{ Female } & \\
\hline & Prevalence & $\%$ & Prevalence & $\%$ & \\
\hline Neck & 242 & $62.0 \%$ & 193 & $77.2 \%$ & $0.00^{*}$ \\
\hline Upper back & 226 & $57.9 \%$ & 135 & $54.0 \%$ & 0.32 \\
\hline Lower back & 242 & $62.0 \%$ & 192 & $76.8 \%$ & $0.00^{*}$ \\
\hline Right shoulder & 236 & $60.5 \%$ & 189 & $75.6 \%$ & $0.00^{*}$ \\
\hline Left shoulder & 124 & $31.7 \%$ & 103 & $41.1 \%$ & $0.01^{*}$ \\
\hline Right forearm & 113 & $28.9 \%$ & 89 & $35.6 \%$ & 0.07 \\
\hline Left forearm & 96 & $24.6 \%$ & 74 & $29.5 \%$ & 0.16 \\
\hline Right wrist & 128 & $32.8 \%$ & 83 & $33.2 \%$ & 0.92 \\
\hline Left wrist & 73 & $18.7 \%$ & 56 & $22.4 \%$ & 0.25 \\
\hline Right hip/buttock & 56 & $14.3 \%$ & 38 & $15.2 \%$ & 0.76 \\
\hline Left hip/buttock & 51 & $13.0 \%$ & 28 & $11.2 \%$ & 0.58 \\
\hline Right thigh & 48 & $12.3 \%$ & 31 & $12.4 \%$ & 0.97 \\
\hline Left thigh & 41 & $10.5 \%$ & 23 & $9.2 \%$ & 0.58 \\
\hline Right knee & 31 & $7.9 \%$ & 27 & $10.8 \%$ & 0.22 \\
\hline Left knee & 28 & $7.1 \%$ & 23 & $9.2 \%$ & 0.35 \\
\hline Right lower leg & 46 & $11.7 \%$ & 38 & $15.2 \%$ & 0.21 \\
\hline Left lower leg & 29 & $7.4 \%$ & 27 & $10.8 \%$ & 0.14 \\
\hline
\end{tabular}

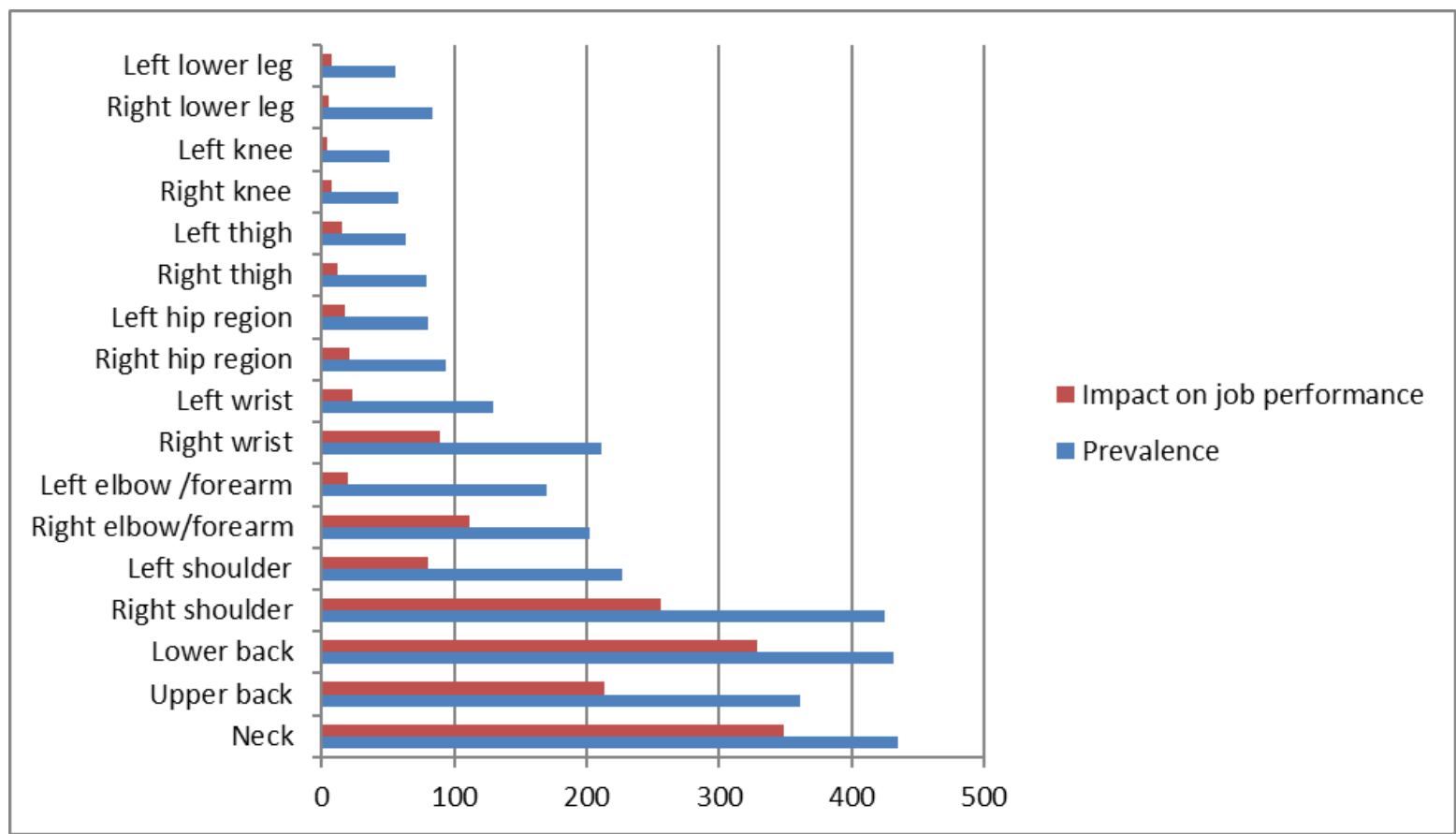

Figure:1 - Prevalence of WMSDs and impact on job performance 
Figure-1 shows the proportion of participants whose job performance was affected by musculoskeletal discomfort. Discomforts in neck (80.2\%), Lower back (76.1\%) and right shoulder $(60.2 \%)$ are greatly shown impact on job performance, whereas discomfort in knees (7.8\%) and lower leg (14.2\%) has very minimal effect on work performance.

\section{DISCUSSION}

Computer usage with longer hours sitting can leads to musculoskeletal symptoms in IT professionals. It was observed that in this study, participants reported most common musculoskeletal strain in neck, upper back, lower back and both shoulders during the past 7 days. These findings are consistent with previous study results. Computer work is often requiring prolonged sitting, which has been shown to be a risk factor for musculoskeletal symptoms. Prolonged sitting with poor workstation ergonomics may cause continuous static contraction of muscles, builds up more tension in muscles and ligaments, decreased muscle flexibility, weakened muscle strength and such changes results in musculoskeletal strain or injuries.

In the present study, the prevalence rate for women was significantly higher compared to men, which is similar with previous studies. The gender difference in prevalence rate may result from women less likely has the history sports and fitness activities, anthropometric reasons, diet and nutrition factors and differences in stress management between men and women.

Majority of participants reported these musculoskeletal discomforts are interfered with their work performance as well as daily activities. Most of the participants consulted healthcare professionals because of neck and lower back symptoms. Also, they shown more impact on job performance like getting frequent intervals from work and often absent to work. Discomforts in other body regions are also reported by fewer participants, but their impact on work is negligible.

\section{CONCLUSION}

This study found that IT professionals with prolonged sitting work felt musculoskeletal discomforts most commonly in neck, back and shoulders. Women are at high risk than men. Neck pain and lower back pain are most common symptoms often require medical attendance. Also, they directly interfere with work performance and daily activities.

\section{Further research}

IT professionals perform predominantly sedentary work with prolonged sitting and musculoskeletal symptoms or discomforts occurrence is very common. This suggests the need to develop a specific prevention program at workplace. Further studies should focus on designing work-related musculoskeletal risk assessment programs in order to prevent or reduce prevalence of symptoms.

\section{Limitation of study}

The limitations of the study include recall bias of the self reported questionnaire. Moreover, physical activity levels (overuse/underuse) of participant not included in study. Another limitation is unequal number of men and women in sample size.

\section{ACKNOWLEDGEMENT}

The author would like to thank all the IT professionals who volunteered to participate in this study.

Conflict of Interest: None declared

Source of Funding: None

Ethical Approval: Approved

\section{REFERENCES}

1. Supriya Vinod, Arun Balasubramanian. (2015). Prevalence of Various WorkRelated Musculoskeletal Disorders in 
Software Professionals. IJMHS. 02 (01), 0913.

2. Melek Ardahan et al. (2016). Analyzing musculoskeletal system discomforts and risk factors in computer-using office workers. Pak J Med Sci. 32 (6), 1425 -1429

3. S. Arun Vijay. (2013). Work related Musculoskeletal Health Disorders among Information Technology Professionals in India: A Prevalence Study. International Journal of Management Research and Business Strategy. 2 (2), 2319 - 2345.

4. Pascal Madeleine. (2013). Computer work and self-reported variables on anthropometrics, computer usage, work ability, productivity, pain, and physical activity. BMC Musculoskeletal Disorders. 14 (226).

5. Srilatha et al. (2011). Prevalence of WorkRelated Wrist and Hand Musculoskeletal Disorders (WMSD) among Computer Users, Karnataka State, India. Journal of Clinical and Diagnostic Research 5 (3), 605607

6. Rajinder Kumar Moom et al. (2015). Prevalence of Musculoskeletal Disorder among Computer bank Office Employees in Punjab (India): A Case Study. Procedia Manufacturing. 3, 6624-6631.

7. Cristiane S. Moriguchi et al. (2019). An Instrumented Workstation to Evaluate Weight-Bearing Distribution in the Sitting Posture. Safety and Health at Work. 10, 314-320.

8. Szu-Ping Lee. (2o18). Gender and posture are significant risk factors to musculoskeletal symptoms during touch screen tablet computer use. The Journal of Physical Therapy Science. 3o (6), 855-861.

9. Beibei Feng et al. (2014). Prevalence of work-related musculoskeletal symptoms of the neck and upper extremity among dentists in China. BMJ open. 4 (10),006451

10. Mohamed Sherif Sirajudeen et al. (2018). Work-related musculoskeletal disorders among faculty members of college of Applied Medical Sciences, Majmaah University, Saudi Arabia: A cross-sectional study. International Journal of Health Sciences. 12 (4)
11. Shariat et al. (2016). Prevalence rate of Musculoskeletal Discomforts based on Severity level among Office Workers. Acta Medica Bulgaria. 153 (1)

12. DO Odebiyiet al. (2016). Prevalence and Impact of Work-related Musculoskeletal Disorders on Job Performance of call Centre Operators in Nigeria. International Journal of Occupational and Environmental Medicine. 7 (2), 98-106.

13. Happiness Anulika Aweto et al. (2015). Prevalence of Work-related Musculoskeletal Disorders Among Hairdressers. International Journal of Occupational Medicine and Environmental Health. 28(3), 545-555.

14. Fairborz Mohammadipour et al. (2018). Work-related Musculoskeletal Disorders in Iranian Office Workers: Prevalence and Risk Factors. Journal of Medicine and Life. 11 (4), 328-333.

15. Claudia Piper et al. (2019). Evidence of Workplace Interventions - A Systematic Review of Systematic Reviews. Int.J.Environ. Res. Public Health. 16, 3553.

16. A Shariat et al. (2016). Prevalance rate of Musculoskeletal Discomforts based on Severity level among Office Workers. Acta Medica Bulgaria. 43 (1)

17. Sayed Tantawy. (2019). Work-related Musculoskeletal Symptoms among Employees with Different Tasks: Ahila Univesity case Study. Biomedical Research. 30

18. Mohamed Sherif Sirajudeen. (2018). Workrelated Musculoskeletal disorders among faculty members of college of Applied Medical Sciences, Majmaah University, Saudi Arabia: A cross-sectional study. International Journal of Health Sciences. 12 (4), 18-25.

How to cite this article: Madhubabu Kothapalli. Prevalence of self-reported work-related musculoskeletal symptoms among software employees in Hyderabad, India. International Journal of Research and Review. 2022; 9(1): 69-73. DOI: https://doi.org/10.52403/ijrr. 20220111 